\title{
Feral Cats Threaten French Polynesian Biodiversity of Inhabited Islands: Effects of Introduced Rodent Assemblage
}

\author{
Palmas P. ${ }^{1,2}$, Meyer J.-Y. ${ }^{3}$, Bambridge R. ${ }^{*}$, Chailler E. ${ }^{1}$, De Méringo H. ${ }^{2,4}$, Teatiu G. ${ }^{~, ~ T e a t i u ~ S . ~}{ }^{\text {, }}$ \\ Timau T. ${ }^{*}$, Maihota N. ${ }^{5}$ and Gaertner J.-C. 1,5 \& Vidal E. ${ }^{6}$ \\ ${ }^{1}$ Univ. Polynesie Francaise, Ifremer, Ilm, Ird, Eio Umr 241, Tahiti, French Polynesia \\ ${ }^{2}$ Institut Méditerranéen de Biodiversité et d'Ecologie marine et continentale (IMBE), Aix Marseille Université, \\ CNRS, IRD, Avignon Université, Centre IRD de Nouméa, BPA5, 98848 Nouméa cedex, Nouvelle- \\ Calédonie \\ ${ }^{3}$ Délégation à la Recherche, Gouvernement de la Polynésie française - B.P. 20981, 98713 Papeete, Tahiti, \\ French Polynesia \\ ${ }^{4}$ Institut Méditerranéen de Biodiversité et d'Écologie marine et continentale (IMBE), Aix Marseille Université, \\ CNRS, IRD, Avignon Université, Europôle de l'Arbois, BP 80, 13545, Aix-en-Provence, France \\ ${ }^{5}$ IRD, UMR-241 EIO, Labex Corail, FAA'A, Tahiti, French Polynesia \\ ${ }^{6}$ UMR ENTROPIE (IRD, Université de La Réunion, CNRS, Université de La Nouvelle-Calédonie, Ifremer), \\ Centre IRD, BP A5, 98848 Nouméa, New Caledonia \\ * Volunteers from the islands of Tahiti, Tahuata, Ua Huka, French Polynesia
}

\begin{abstract}
Invasive populations of feral cats strongly threaten the native fauna on islands worldwide. French Polynesia, located in the South Pacific, is included within the 36 global biodiversity hotspots and harbors several highly endangered endemic species. Domestic cats have been introduced by European settlers ca. 200yrs BP and feral and domestic cat populations are now present in most French Polynesia islands and their habitats, but their abundance and impacts remain largely understudied. The French Polynesian islands represent a multi-invaded system that exhibit contrasted assemblages of introduced rodents. The impact of feral cat populations is assumed to be higher in presence of introduced rodents and may also vary according to the rodent species. Here, we investigated the trophic ecology and impact of feral cats on four contrasted inhabited tropical islands, regarding the introduced rodent species: two islands in the Marquesas - Ua Huka (harboring only Polynesian rats $R$. exulans) and Tahuata (harboring Polynesian rat and black rat $R$. rattus) - and two islands of The Society: Moorea and Tahiti (harboring Polynesian, black, brown rats $R$. norvegicus). We studied i) cat diet by trophic analyses using feral cat scats samples and ii) cat abundance using camera traps set up during 15 consecutive days giving an abundance index (General Index (GI): mean number of virtual capture per camera per occasion); across 2 surveys (2018-2021) on these four studied islands. Our study reveals previously unreported patterns of cat abundance; in the Marquesas islands, we obtained a GI of $0.46 \pm 0.25$, for Ua Huka $0.73 \pm .23$ and $0.19 \pm 0.03$ for Tahuata. In the Society islands, we obtained a GI of $0.17 \pm 0.15,0.02 \pm 0.01$ for Moorea and $0.32 \pm 0.03$ for Tahiti. Feral cats prey upon at least 13 native bird species in French Polynesian islands, 8 of which are endemics throughout 3 are UICN Red-listed as threatened. Surprising relative abundances revealed more feral cats on islands harboring only one species of rodent (Ua Huka with only Rattus exulans). Bird conservation in the different islands of French Polynesia requires specific studies on invasive predators before implementation of management actions.
\end{abstract}

Keywords: invasive predator; Felis catus; diet; camera trap monitoring; endemic species; birds 